\title{
Literature Review of Historical Building Restoration Technology
}

\author{
Shen $\mathrm{Hu}^{1, *}$, Wenqi Hao ${ }^{2}$ \\ ${ }^{1}$ School of architecture and art,North China University of Technology, Beijing, China \\ ${ }^{2}$ School of architecture and art,North China University of Technology, Beijing, China
}

\begin{abstract}
There are many directions and schools in the research on the restoration of historical buildings. The conflict of values between these directions and schools, the deviation of repair methods and practices, the insufficient performance of restoration technology in historical buildings, and the potential background factors affecting these conflicts and deviations are all factors to be considered. This study analyzes the relevant literature and puts forward the conceptual views, and finally produces a research plan for the extensive discussion and understanding of the literature. In addition, this study also hopes to reveal the substantive problems of unreasonable use or lack of use of historical buildings, demolition of old buildings to build new ones, and disconnection of theory and technology. And find a practical building repair technology
\end{abstract}

\section{Introduction}

Historical architecture is a building structure which has certain protection value and can reflect the local characteristics and historical traces after being determined outside the provisions of the civil insurance unit. Historical buildings can be damaged through a series of repairs and maintenance. However, the basic principles of its restoration are uncertain and different repair points, the use of materials, the prediction of scale, the evaluation of the precious grade of historical buildings are all vague. It is found that the protection and restoration of historical buildings are complicated and difficult. With the accumulation of practice and the deepening of attention to ancient architecture, scholars have explored the recognized principles of restoration and protection. They work not so much to solve complex mega-system problems as to specify a guideline for building restoration value. Related to the important role of value in historical buildings, the so-called restoration and protection principle is the value and experience summarized in the practice of historical building protection and restoration ${ }^{1}$.

\section{Historical background}

The Athenian Charter believes that cultural relics should highlight their historical, archaeological and aesthetic values. Barra believes that cultural meaning refers to the aesthetic, historical, scientific, social or spiritual values of the past, present and future generations. The European Charter of Architectural Heritage defines architectural heritage as covering important monuments, as well as smaller buildings in towns and characteristic villages in natural or artificial environments. The three parts of the architectural heritage are described in more detail in the European Treaty on the Protection of Architectural Heritage: monuments, buildings, and historical sites.

The Nara document points out that the value of the protection of cultural heritage of various types and historical periods lies in its own state.The understanding of the state depends on the authenticity of the value state. The positioning of historical buildings in the Athenian Charter should highlight its humanistic value. Barra believes that the meaning of humanistic value refers to the abstract and concrete value of people in the historical dimension.The core issue is the interpretation of authenticity. Authenticity is the motif of all principles. This is the core principle and idea of international protection concept at present, and also the basic theory of architectural heritage protection.

\section{Methodology of treatment}

In order to comply with the standards of literature review proposed by Webster and Watson, this paper follows the guidelines to create a search record. In addition, this paper clearly states that the selection of samples is based on authenticity, standard type, and attempts to avoid possible favouritism or bias. The literature review is defined by the use of comprehensive retrieval, which uses clear keywords and viscosity to obtain the corresponding information, and the relevant literature selection steps (figure 1 table) are represented.

\footnotetext{
* Corresponding author: 2481618165@qq.com
} 
Table 1. Methods of literature analysis and review.

\begin{tabular}{|c|c|c|}
\hline Phase process & $\begin{array}{l}\text { DIRECTIVES } \\
\text { AND } \\
\text { GUIDANCE }\end{array}$ & $\begin{array}{l}\text { TARGETED } \\
\text { TARGETS }\end{array}$ \\
\hline $\begin{array}{l}01 \quad \text { SELECT } \\
\text { DATABASE }\end{array}$ & $\begin{array}{l}\text { Search and select } \\
\text { different search } \\
\text { libraries }\end{array}$ & $\begin{array}{l}\text { The coverage was } \\
\text { narrowed down to } \\
\text { a more thematic } \\
\text { database }\end{array}$ \\
\hline $\begin{array}{l}02 \text { SELECT } \\
\text { KEYWORD }\end{array}$ & $\begin{array}{l}\text { Search articles, } \\
\text { including titles and } \\
\text { abstracts of } \\
\text { specific keywords }\end{array}$ & $\begin{array}{l}\text { Selection of } \\
\text { appropriate } \\
\text { literature on the } \\
\text { subject }\end{array}$ \\
\hline $\begin{array}{l}03 \text { SPECIFY } \\
\text { FILTER TYPE }\end{array}$ & $\begin{array}{l}\text { Time Limit and } \\
\text { Filtering } \\
\text { Publications }\end{array}$ & $\begin{array}{l}\text { Maintain integrity } \\
\text { and suitability of } \\
\text { research }\end{array}$ \\
\hline $\begin{array}{l}04 \text { DELETE } \\
\text { DUPLICATE } \\
\text { SELECTION }\end{array}$ & $\begin{array}{l}\text { Delete articles that } \\
\text { appear in multiple } \\
\text { databases }\end{array}$ & $\begin{array}{l}\text { Exclusion of } \\
\text { items because } \\
\text { they did not } \\
\text { provide additional } \\
\text { value }\end{array}$ \\
\hline $\begin{array}{lll}05 & \text { THE } & \text { KEY } \\
\text { WORDS } & \text { ARE } \\
\text { NEEDED } & \end{array}$ & $\begin{array}{l}\text { Sticky Analysis of } \\
\text { Key Words }\end{array}$ & $\begin{array}{lr}\text { Ensuring } & \text { their } \\
\text { usefulness } & \text { and } \\
\text { relevance } & \end{array}$ \\
\hline $\begin{array}{lr}06 & \text { PERFECT } \\
\text { FOR } & \text { FULL } \\
\text { TEXT } & \end{array}$ & $\begin{array}{l}\text { Read the abstract, } \\
\text { introduction and } \\
\text { conclusion of the } \\
\text { selected article to } \\
\text { exclude potential } \\
\text { misstatements. }\end{array}$ & $\begin{array}{l}\text { Don't take into } \\
\text { account journal } \\
\text { articles that lack } \\
\text { significant } \\
\text { relevance or } \\
\text { association, and } \\
\text { review the topic } \\
\text { comprehensively }\end{array}$ \\
\hline
\end{tabular}

Search for published articles is limited to China Zhi wang, CNKI Chinese academic journals, Google Academic. Three major databases. preliminary analysis shows that increasing the number of databases will greatly increase the number of duplicate data obtained, and the search is limited to carefully selected keywords (historical architectural values, definitions) in order to leave the most meaningful literature.

In order to ensure substantive relevance, both keywords must appear in the body of the article, analyze the abstract, introduction and conclusion of the remaining papers, and delete those articles that have passed the above selection but are not meaningful to this time. Because the theme of this article is the definition of historical architectural value. Therefore, the study of different topics of pure architectural technology restoration and needle historical architecture is not considered. Finally, through the arrangement of the above conditions, the papers from December 1985 to October 2020 are collected, sorted and selected.

The proportion of journal papers in our sample sources is 49.3 , the master thesis is 33.8 , and the doctoral thesis is 16.9. Most of the articles are in the direction of engineering technology, and a few are philosophy and humanities, economics and management science and social science. Therefore, the main direction of analyzing the value of historical buildings is one engineering science and technology as the leading, other courses to assist the form of participation. It is unfavorable to the large framework of multi-disciplinary blending and can not be regarded as a mature subject of multi-disciplinary nature.

\section{Restoration techniques for historic buildings}

\subsection{Repair design issues}

In the course of the restoration and design of the historical building, we should carry out preliminary research work, understand the non-renewable nature of the historical building, preserve the important historical information of its remains and the authenticity of the building, and then establish a complete design procedure for the restoration and reuse of the building, and realize investigation and research, scientific analysis, program comparison, step by step implementation, and apply the method of modern scientific research to the protection of historical buildings, so that it is divorced from the handicraft method.

Therefore, when repairing and designing historical buildings and surrounding environment, we should protect the humanistic and social value of the region as far as possible, and make the commercial tourism and historical building protection develop harmoniously. In order to link the protection of historical buildings with economic benefits, it is necessary to combine with business to add cultural, religious and cultural innovations, through design. As an important evidence to standardize, build and record the ancient city, the results of aerial survey in ancient city are printed into atlas, and also become the documents to record the present. Among them, there are some basic principles for repairing design problems: first, the most important core principle-reality problem. Reflected in the environment, material, technology three basic aspects. Second, secondary principle, minimum intervention principle: to maximize the protection and maintenance of authenticity, as far as possible to reduce the original construction.

\subsection{Remedial technical problems}

\subsubsection{Historic Buildings Community Protection Technology}

In the aspect of historical community protection, high and new technology is adopted, which involves a complex system, including the following steps:

1. use computer to establish historical settlement, historical building technology archives. The community, square, ruins, sculpture, color painting, landscape and other important data into the database, improve the base efficiency.The planning department of some large and medium cities will adopt auxiliary design at the same time. Nowadays, more and more urban restoration designs in the world begin to use $3 \mathrm{~s}$ (GI S, GP S, R) technology, 
especially the use of urban geographic information system technology to establish urban spatial information system, the comprehensive use of $3 \mathrm{~S}$ technology, the ancient city restoration design and individual building restoration and design work, the historical building from static protection to dynamic

Renewal of the transformation process of information, digitization.

2.Technology to repair historical buildings. The technology of electronic and industrial departments, such as location of cloud bitmap, simulation imaging of electronic frequency return intervention, processing of program-controlled machine tools and new synthetic materials, is applied to the restoration of historical buildings.

3.The environmental protection facilities and technologies are applied to the building environment and monitoring, the monitoring is random, and a comprehensive treatment scheme is put forward.

\subsubsection{History Building Protection Technology}

\subsubsection{Remediation of masonry structures}

Repair methods:

whole replacement: before use, it is necessary to detect the damage state of the wall, the building with high historical value, which can not be solved by cleaning and strengthening technology. The technical method is to clean the surface of the external wall, pull out the damaged brick, and re-stitch the new brick in situ.The material of the replacement brick is very important, the building itself block is the most suitable. But the quantity is insufficient. If the original brick is not available, choose the replacement brick. The replacement bricks shall match the bulk building bricks in appearance, correspondence, and durability.Historical Noumenon building itself brick size is generally non-standard, need special custom brick. It is necessary to analyze the composition of bricks, firing temperature, color and so on, so as to provide the basis for the search and preparation of replacement bricks in the future. The whole replacement of degraded stone is also called inlay (or digging). The deterioration or damage of the stone to be replaced reaches the degree of damage to the integrity of the structure, and the inlay is also used to describe the local deterioration of the removed and replaced stone. The new stone may bring a visual sense of suddenness, and the original stone may be more appropriate.

\subsubsection{Woodwork Restoration}

Wood protection is generally expressed by physical and chemical methods.

The physical method is to change the microclimate of wood components or redesign the architecture. Some foreign civil insurance personnel often emphasize the reversibility of restoration and oppose the improvement of the environment of cultural relics in historical buildings. Then part of the filling repair is carried out, the method is to fill the gap of wood into cork and glue it, using the strong adsorption of cork to separate it from the outside world, and the ability of water body to enter the wood seam is weakened.In fact, for cultural relic buildings, the new architectural design can change the climate around the building environment, which has a high degree of intervention and low practicality; for historical buildings with good existing conditions and high durability of materials, it may be a good choice to improve the environmental conditions.

1. end splitting. The longitudinal cracking of the end along the wood texture is a common defect of wood, which occurs at the hinge joint of truss. This failure will reduce the stress and torsion bearing capacity of wood structure.

2. internal longitudinal splitting. Only in the interior of the structure. The effect on tension and pressure is small, but it will reduce shear resistance.

3. the structure cut open. In an unusual disaster, the structure is completely broken, causing sudden damage, often resulting in a decline in the pull of wood.

\subsection{Structural reinforcement design}

The European Agency for Open Profit Technology Eureka proposed a new technology for strengthening masonry and concrete buildings by replacing masonry structures with carbon fiber composites (FPR) by material restoration. The method is to put carbon fiber into epoxy resin or polyethylene resin, produce unidirectional prepreg thin layer, act on weathered or damaged buildings to make the building stable, especially in columns and gables. The aim is to reduce some historical buildings, monuments and other civil engineering structures damaged by weathering, pollution and urban life by using the low intrusive properties of composites. This kind of reinforcement technology causes less damage to the original building structure than the traditional technology. The carbon fiber prepreg is corrosion resistant, light weight, convenient storage and transportation, convenient construction, no need to strengthen the damaged structure of the building, suitable for forming film on the surface of irregular buildings. the greatest benefit lies in the reversibility of the material,. It can be solidified at low temperature, so there is no need to change the equipment greatly, thus reducing the construction cost. This technology has been used in the restoration of many masonry structures in Europe and the United States.

At present, epoxy resin injection and steel plate and reinforcement are used to repair and reinforce modern historical buildings. Less damage to the wall it will loose brick replacement, crack injection epoxy resin. The wall with serious structural problems or joint adhesion is filled with resin mortar, fixed with steel structure and bolt, and epoxy resin mixed with fiber between steel plate and wall to enhance its resistance. At present, fiber reinforced composites used in construction are mainly polymers and their derivatives. 


\section{Conclusion}

At present, the biggest problem in the field of protection and restoration of historical buildings in China is the disconnection between restoration and practice, and this phenomenon is still produced under the condition of continuous advancement of theory and technology, indicating that there are defects in the study of its methodology between theory and practice. This problem is manifested in that repair theory is difficult to accurately guide practice by a standard. To be exact, from the purpose of protecting repair, the principle of protecting repair to the application of repair technology, the options are too complicated and the edges are too much. As a descriptive science, the above problems are normal.

Philosophy and other disciplines must be used in practice and methods to solve it. Therefore, the viewpoint and method of value theory and evaluation has become the only way to establish a highly operable protection and restoration system for historical buildings.First, in addition to its historical value, historical architecture is also important in culture, science and emotion. How to make these values realize under the premise of protection, there is no clear boundary and clear explanation of these values belong to gray zone, the boundary is vague. Secondly, for people's unequal aesthetic, protection consciousness and execution ability, and protection will inevitably limit the development of some modern economic industries and the promotion of modern life style, so in the fuzzy boundary defined by historical buildings, non-historical buildings tend to dominate. Third, the complexity of historical architectural value is obvious in scarcity.

\section{References}

1.Seaton Hugh., S . (2020), The Construction Technology Handbook, 15-17.

2.John J. McGowan., J . (2020), Energy and Analytics. BIG DATA and Building Technology Integration (to be published)

3.Tao Zhang, Lei Shi,Zhen Tan ,T .S . (2017), Analysis on Construction Technology and Construction Measures of Isolation Structure. Journal of Research in Science and Engineering. 84-86.

4.Luigi T, L (2017), Patent Issued for Bandwidth Dependent Media Stream Compression . 56-58. 